\title{
Hydrothermal liquefaction of biomass produced from domestic sewage treatment in high-rate ponds
}

\author{
Eduardo Aguiar Couto a, *, Filomena Pinto ${ }^{\mathrm{b}}$, Francisco Varela ${ }^{\mathrm{b}}$, Alberto Reis ${ }^{\mathrm{b}}$,

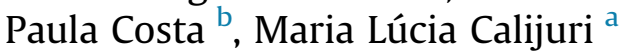 \\ ${ }^{a}$ Federal University of Viçosa (Universidade Federal de Viçosa/UFV), Departament of Civil Engineering, Environmental Engineering Group - nPA, Campus \\ Viçosa, 36570-000 Viçosa, MG, Brazil \\ b Laboratório Nacional de Energia e Geologia, I.P., Unidade de Bioenergia, Estrada do Paço do Lumiar 22, 1649-038 Lisboa, Portugal
}

\section{A R T I C L E I N F O}

\section{Article history:}

Received 13 March 2017

Received in revised form

13 June 2017

Accepted 14 November 2017

Available online 15 November 2017

\section{Keywords:}

Microalga

Bio-oil

Biorefinery

Hydrothermal liquefaction

Thermochemical conversion

\begin{abstract}
A B S T R A C T
This study evaluates the application of biomass produced from the treatment of domestic sewage in high-rate ponds (HRPs) as feedstock for the production of bio-oil via hydrothermal liquefaction (HTL). The effects of reaction time, temperature, and biomass/water ratio on the yield of bio-oil were assessed. In addition, a balance of carbon and nitrogen among the products (bio-oil, aqueous phase, solid residue, and gas) was carried out, in order to evaluate the quality of the bio-oil and possibilities for increasing value from the byproducts. In a 15 -min operation at $300^{\circ} \mathrm{C}$ with biomass/water ratio of $1 / 10\left(\mathrm{w} . \mathrm{w}^{-1}\right)$, the bio-oil yield was of $44.4 \%$ (Dry Ash Free - daf-basis). Under every condition tested, the solid residue was the most abundant byproduct, mostly due to the high ash content in the biomass. The minimum nitrogen recovery in the bio-oil was $57 \%$, obtained in the operation at $275{ }^{\circ} \mathrm{C}$, which is considered the main disadvantage of the process. The use of biomass directly after its production may result in an excessive consumption of energy due to the high water content. However, the need for drying is reduced when compared to other microalgal-based bioenergy production processes, potentially achieving a positive energy balance in the HTL.
\end{abstract}

(๑) 2017 Elsevier Ltd. All rights reserved.

\section{Introduction}

Energy dependence on fossil fuels is associated with the accumulation of atmospheric pollutants including greenhouse gases, which may harm the environment and pose problems to the human health. Therefore, there is an increasing interest in the development of new and sustainable processes for producing energy from renewable sources with the aim of reaching net-zero carbon emissions. In addition, these new energy sources must be capable of meeting the current global energy demand. In this context, the Intergovernmental Panel on Climate Change [1] states that the sustainability of the planet depends on the capacity to provide sufficient clean and sustainable energy to meet the demands of future generations.

Microalgae biomass is widely identified as a promising feedstock for the production of third generation biofuels. Microalgae are organisms that may present autotrophic metabolism with greater

\footnotetext{
* Corresponding author.

E-mail address: eduardo.acouto@hotmail.com (E.A. Couto).
}

photosynthetic efficiency, growth rate and yield/area ratio than other energy crops [2]. In addition, they can be cultivated throughout the year, in areas unfit for agriculture, and in most climates [3].

Despite such advantages, there are still challenges to the largescale use of microalgae biofuels, mostly related to its high production costs and to difficulties in obtaining a positive energy balance. The axenic culture of species with high lipid content has high water and nutrients demands, in addition to being susceptible to contamination by species with low lipid content, and bacteria, which present faster growth. Another important aspect is the energy demand of biomass drying, which can be responsible for up to $50 \%$ of the energy consumption in the microalgae oil production process [4].

In the search for a solution to the aforementioned issues, several studies addressed the use of wastewater as a cultivation medium for a consortium of microalgae and other microorganisms [5-7], with the objective of reducing the production costs relative to those of water and nutrients. The significant advantage of this is the production of treated effluent as a byproduct of biomass production, in conditions to be used for several non-potable purposes. The 